\title{
Compact Printed Slot UWB Monopole Antenna with Ground Plane Slit
}

\author{
M.E.Sundaravel, Vallikannu AL, Himanshu Sheker \\ Department of Electronics and communication Engineering, Hindustan University, India.
}

\begin{abstract}
A compact printed slot monopole antenna for Ultra Wide Band (UWB) communications is presented. The antenna design is enhanced by introducing a slit in ground plane and symmetrical tappers in radiation patch to achieve a significant improvement in the impedance bandwidth. In addition to that, two symmetrical slots on radiation patch acts as load to match the impedance and to cause good radiation performance in both sides. The proposed antenna is designed using LTCC substrate with the material DuPont 951. Parameters are optimized through numerical modeling. It is observed from the results that the proposed antenna has minimum reflection loss in the ultra-wide radio band with effective radiation characteristics
\end{abstract}

Keywords: Impedance bandwidth, LTCC substrate, Monopole antenna, UWB.

\section{INTRODUCTION}

Ultra Wide Band (UWB) technology is a challengeable area in the field of antennas development. Ultra-wideband is a technology for transmitting information spread over a large bandwidth, usually greater than $500 \mathrm{MHz}$. Recently, researchers show much interest in developing ultra-wide band radio for short-range high speed indoor wireless communication networks. Ultra-wideband characteristics are well-suited to short-distance applications due to low emission levels permitted by regulatory agencies and hence, it easily supports high data rates between wireless PC peripherals. A planar antenna in Low - Temperature Cofired Ceramic (LTCC) with transceiver integration capability of UWB can be cancelled the effects of path loss in a transmission system [1]. An ultra wide band slot antenna with microstrip line feed in LTCC technology is developed for a single-package solution of ultra wide band radio communication systems [2], [3]. An UWB is achieved by using co-planar waveguide (CPW) fed circular disc monopole antenna with various radiuses of circular disc [4]. Modern communication systems require covering allocated wireless frequency bands with a single antenna. Planar printed monopole antennas due to their attractive features such as, low cost, simple structure, ease of fabrication, wide operating band and omnidirectional radiation characteristics have received great attention for UWB systems [5]-[11]. Moreover, design of a multiband antenna which also covers the UWB radio range without deteriorating the UWB performance is of high interest. From the literature review, two techniques are highlighted to create multiband printed monopole antennas. In the first technique, a radiating element (patch) is designed to cover the desired wide frequency band. The large size of the antenna increases the lower limit of the frequency band. The multiband behavior is obtained by introducing notches into the antenna [12], [13]. The second technique is designing a small size antenna in order to achieve highest frequency bands and by adding extra resonant elements to the main element, lower frequency bands are created [14], [15].

In this paper, a compact printed slot UWB monopole antenna is proposed. The proposed antenna achieves ultra-wide bandwidth by introducing a slit in ground plane and symmetrical tappers in radiation element. Symmetrical slots are formed on the radiation element to cause good radiation performance in both sides (back and front) and maintain the impedance match over the operating UWB range. The proposed antenna has a compact size of $17.3 \times 12 \times 1 \mathrm{~mm}^{3}$. The measured $10 \mathrm{~dB}$ reflection coefficient shows that the proposed antenna achieves a bandwidth ranging of $4.1-10 \mathrm{GHz}$. The proposed antenna presents omnidirectional radiation patterns across the whole operating band in the $\mathrm{H}$-plane.

\section{ANTENNA DESIGN AND CONFIGURATION}

In Fig.1, the geometry of the printed slot UWB monopole antenna is proposed. It consists of a rectangular radiation patch with symmetrical tappers placed on the lower side of the patch. Symmetrical slots placed on the tappers side of the patch and a rectangular ground plane with a slit located on its center of upper side is used in the antenna design. Slit and tappers with dimensions $\mathrm{W}_{\text {slit, }}, \mathrm{L}_{\mathrm{slit}}, \mathrm{H}_{\mathrm{t}}$, and angle $\left(\theta_{\mathrm{t}}\right)$ play a significant role in achieving a broad operating bandwidth. Symmetrical slots with side lengths $\left(L_{\text {slot }}\right)$ act as load to match the impedance between feed line and radiation patch and to cause good radiation performance in both sides. 


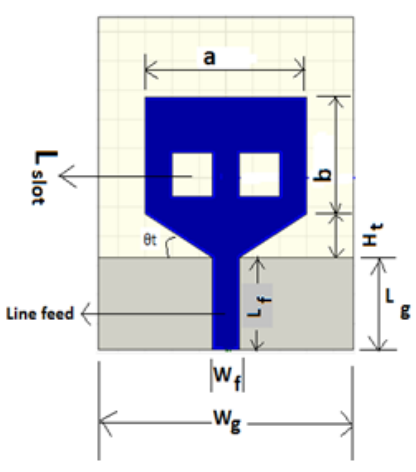

(a)

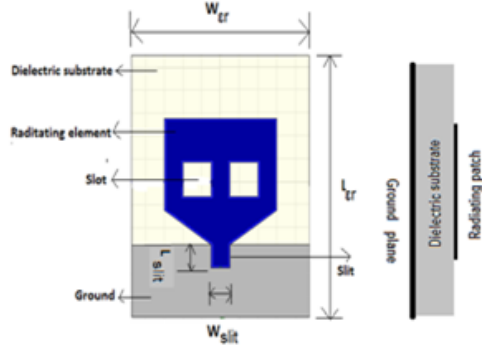

(b)

(c)

Figure 1. Configuration of the proposed ground slit printed slot UWB monopole slot antenna (a) Front view, (b) Back view, (c) Side view.

A $50 \mathrm{ohm}$ microstrip line of width $\left(\mathrm{W}_{\mathrm{f}}\right)$ is connected to the radiation patch as feed line. Fig. 1(a) shows the radiation patch with dimensions $(\mathrm{a}, \mathrm{b})$ and feed line with dimensions $\left(\mathrm{W}_{\mathrm{f}}, \mathrm{L}_{\mathrm{f}}\right)$ are printed on the top side of the substrate while the ground plane is printed on the bottom side of the substrate. For a desired resonant frequency the guided wavelength is given by

$$
\lambda_{g}=\frac{\lambda_{r}}{\sqrt{\varepsilon_{r e f f}}}=\frac{c}{f_{r} \sqrt{\varepsilon_{r e f f}}}
$$

where $\mathrm{c}$ is the speed of light, $\lambda_{\mathrm{r}}$ is the free-space wavelength of the monopole antenna resonant frequency $\mathrm{f}_{\mathrm{r}}$ and $\varepsilon_{\text {reff }}$ is the relative effective permittivity of the substrate which is given by the approximate formula of

$$
\varepsilon_{\text {reff }} \approx \frac{\varepsilon_{r}+1}{2}
$$

The length of monopole antenna is usually equivalent value of quarter wavelength. The approximate value for the length (b) of proposed monopole radiation patch is given by

$$
b \approx \frac{\lambda_{g}}{4}
$$

The antenna is simulated on LTCC substrate with material Dupont 951, with its relative permittivity and loss tangent of 7.8 and 0.0015 respectively. The simulation is carried out with High Frequency Simulation Software (HFSS) [16]. A prototype of the proposed printed slot UWB monopole antenna with optimal design, i.e., $\mathrm{L}_{\varepsilon \mathrm{r}}=$ $19 \mathrm{~mm}, \mathrm{~W}_{\mathrm{rr}}=22.8 \mathrm{~mm}, \mathrm{a}=12 \mathrm{~mm}, \mathrm{~b}=8 \mathrm{~mm}, \mathrm{~L}_{\text {slot }}=2 \mathrm{~mm}, \mathrm{~L}_{\mathrm{g}}=6.3 \mathrm{~mm}, \mathrm{~W}_{\mathrm{g}}=19 \mathrm{~mm}, \mathrm{H}_{\mathrm{t}}=3 \mathrm{~mm}, \theta_{\mathrm{t}}=45^{\circ}, \mathrm{L}_{\mathrm{slit}}=$ $2 \mathrm{~mm}, \mathrm{~W}_{\text {slit }}=2 \mathrm{~mm}, \mathrm{~W}_{\mathrm{f}}=2 \mathrm{~mm}$ and $\mathrm{L}_{\mathrm{f}}=6.3 \mathrm{~mm}$ as shown in Fig. 1 .

\section{Antenna Performance}

The proposed printed slot UWB monopole antenna is simulated and its port is excited by 50 ohm impedance. Simulated reflection co- efficient $\left(S_{11}\right)$ of the proposed antenna from $4.1 \mathrm{GHz}$ to $10 \mathrm{GHz}$ over 10dB is shown in Fig.2. The simulated resistive and reactive components characteristics of the input port are shown in Fig.3. It explains the impedance match between the feed line and radiation element over the frequency operation in ultrawide bandwidth. Fig.4 shows the surface current distributions at different frequencies called 4.5, 5.5, 6.5, 7.5, 8.5 and $9.5 \mathrm{GHz}$ over the UWB range. In Fig.5, the simulated radiation patterns at different frequencies called 4.5, 5.5, 6.5, 7.5, 8.5 and $9.5 \mathrm{GHz}$ in both E-plane and H-plane are shown. It is observed that the patterns of the proposed antenna presents omnidirectional and stable radiation characteristics in the $x-y$ plane $(H-p l a n e)$ over the operating frequency range of $4.1 \mathrm{GHz}$ and $10 \mathrm{GHz}$. The $\mathrm{x}-\mathrm{z}$ plane (E-plane) patterns show good agreement of radiation performance in UWB operation. Fig.6 shows the gains of the realized antenna from 4.1- 10GHz. It indicates that the proposed antenna gives increasable gain while increases the frequency over the operation bandwidth. 


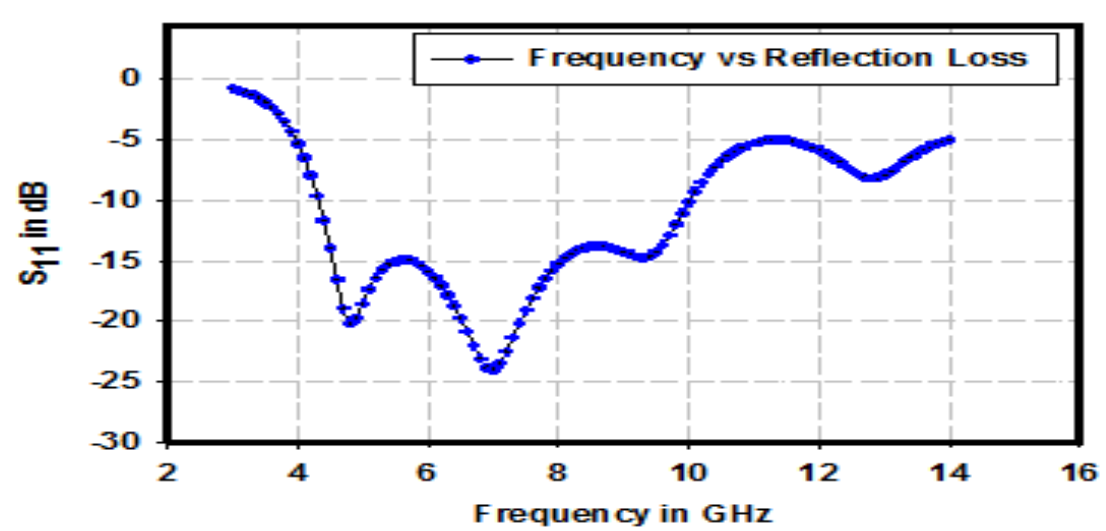

Figure 2. Simulated reflection coefficient of the proposed UWB antenna.

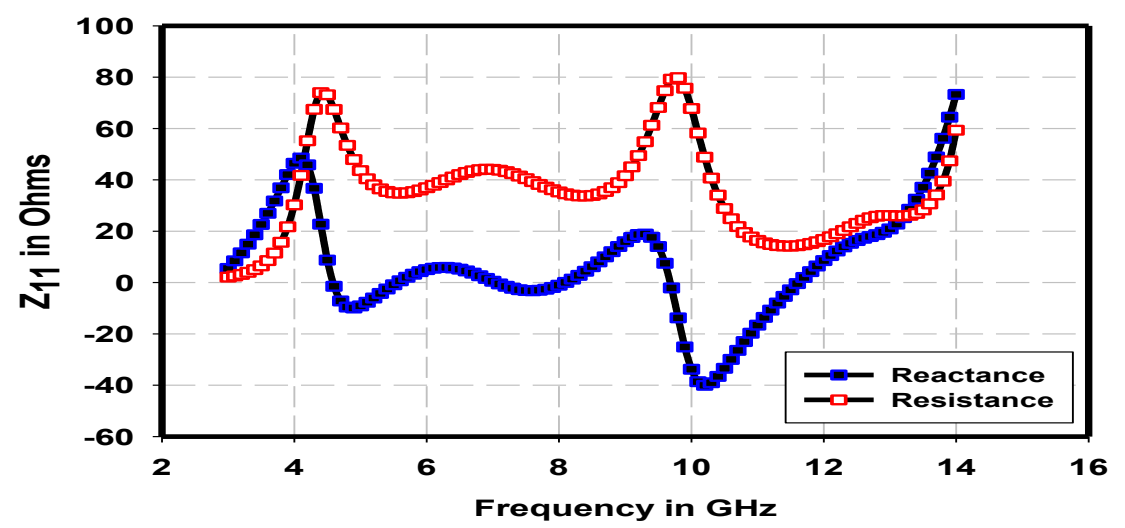

Figure 3. Simulated impedance components of the proposed UWB antenna.

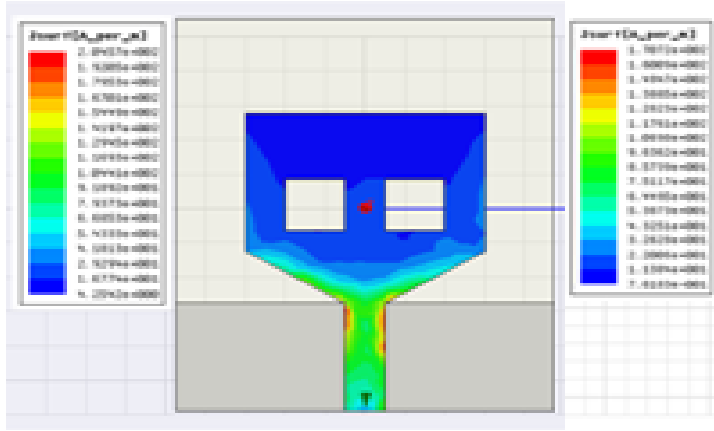

$\mathrm{f}=4.5 \mathrm{GHz}$

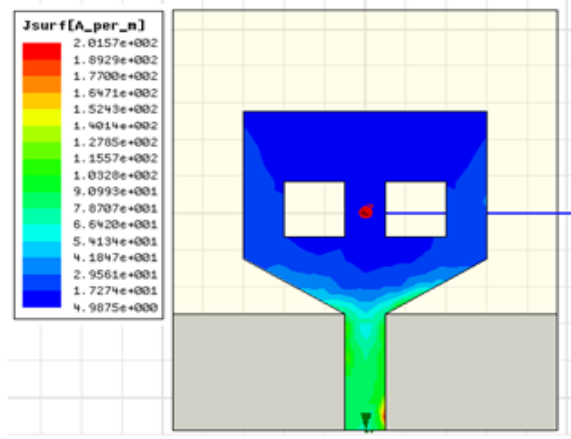

$\mathrm{f}=6.5 \mathrm{GHz}$

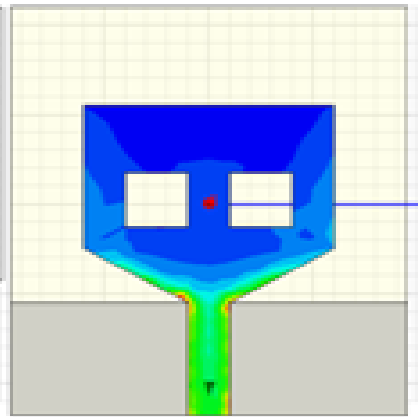

$\mathrm{f}=5.5 \mathrm{GHz}$

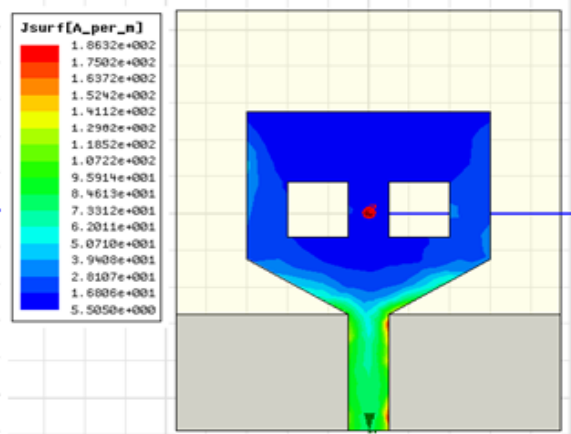

$\mathrm{f}=7.5 \mathrm{GHz}$ 


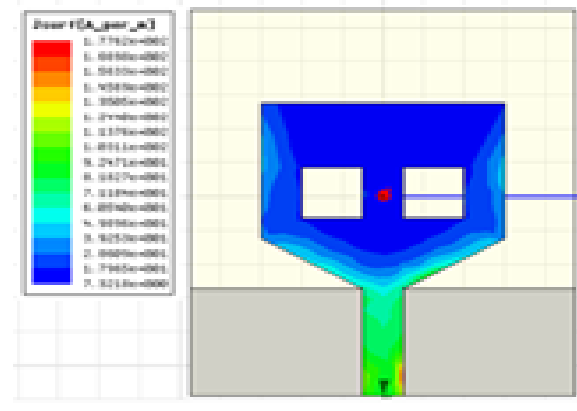

$\mathrm{f}=8.5 \mathrm{GHz}$

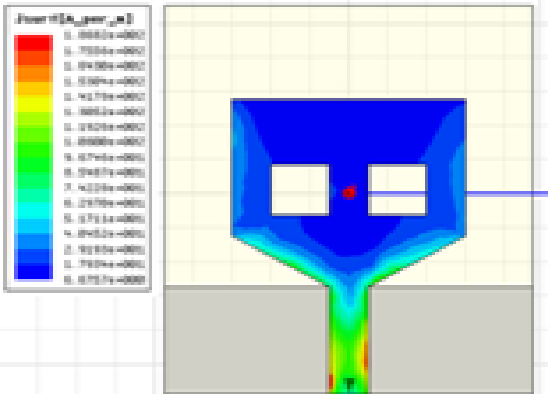

$\mathrm{f}=9.5 \mathrm{GHz}$

Figure 4. Simulated current distribution of the proposed UWB antenna at different frequencies

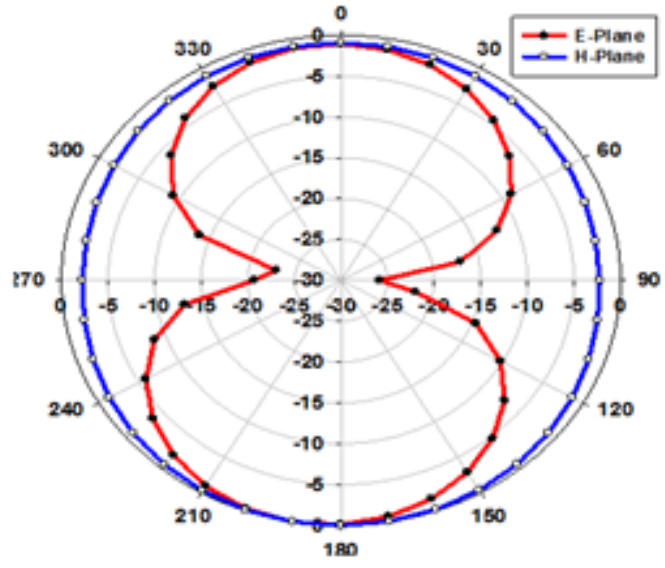

$\mathrm{f}=4.5 \mathrm{GHz}$

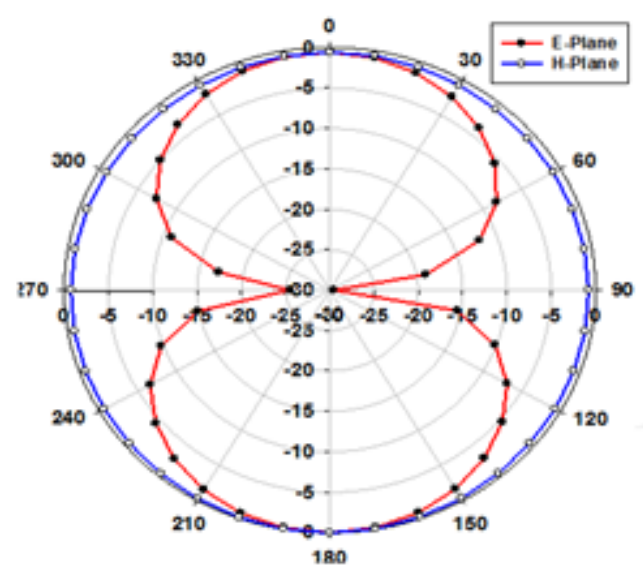

$\mathrm{f}=6.5 \mathrm{GHz}$

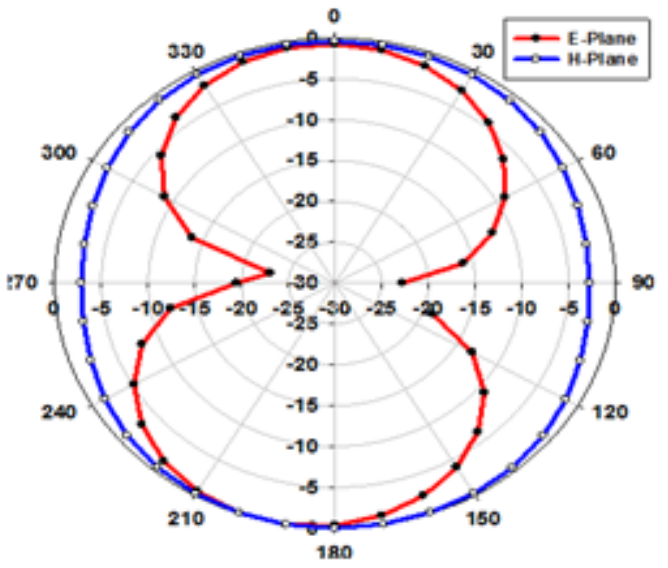

$\mathrm{f}=5.5 \mathrm{GHz}$

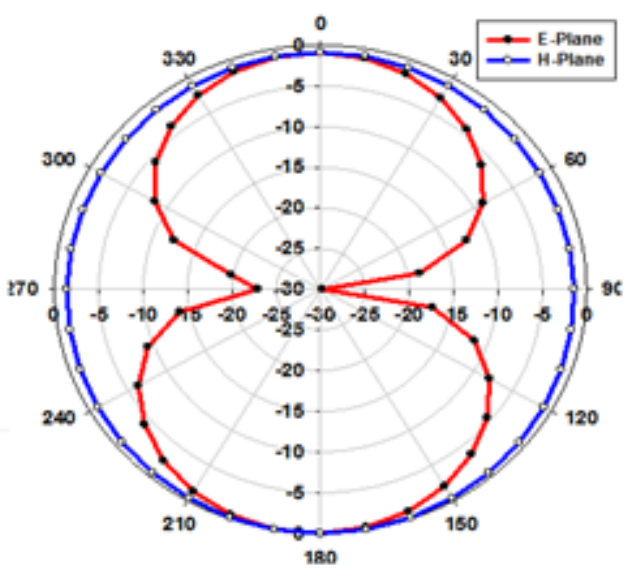

$\mathrm{f}=7.5 \mathrm{GHz}$ 


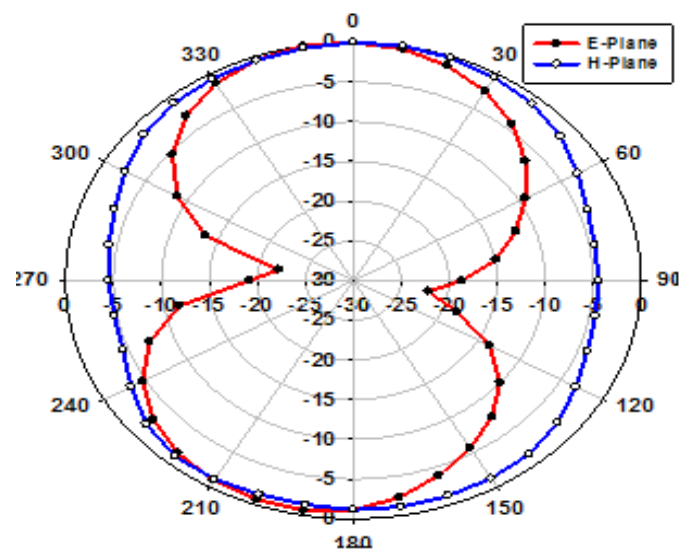

$\mathrm{f}=8.5 \mathrm{GHz}$

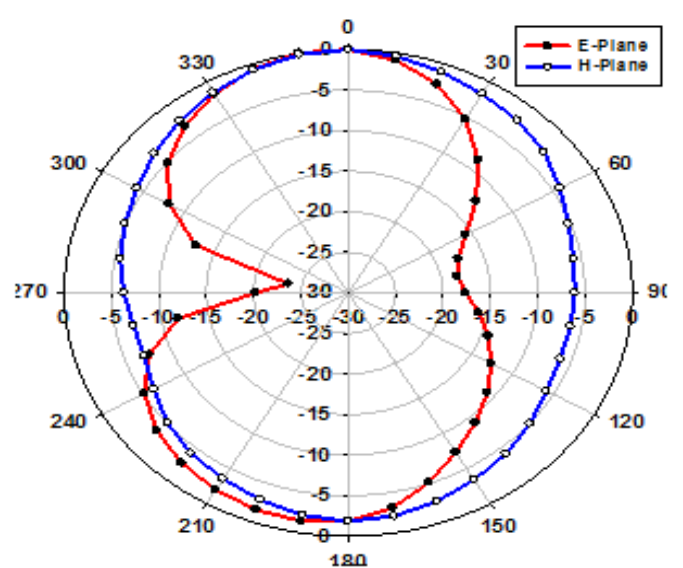

$\mathrm{f}=9.5 \mathrm{GHz}$

Figure 5. Simulated E-Plane and H-Plane radiations of proposed slot UWB Monopole antenna at different frequencies.

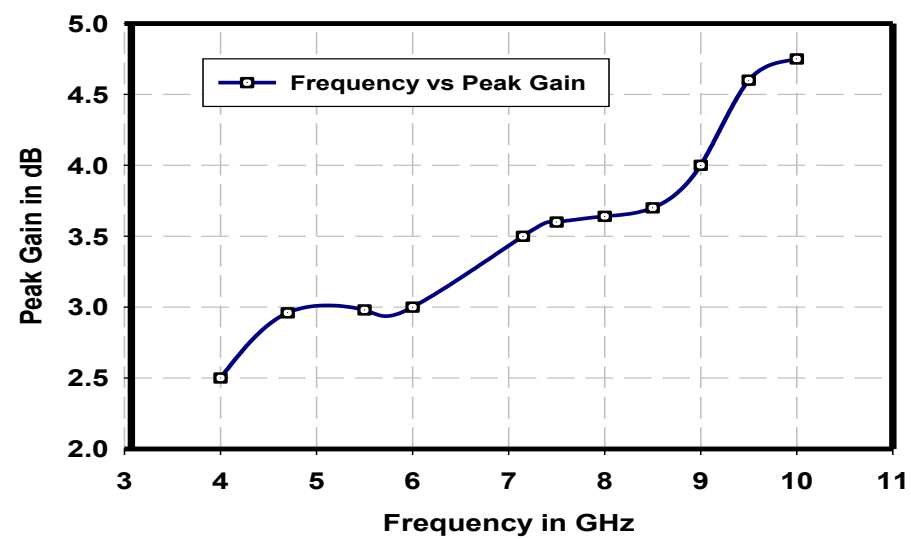

Figure 6. Simulated peak gain of the proposed UWB monopole antenna.

IV.

CONCLUSION

A microstrip line fed compact printed slot monopole antenna with ground plane slit is proposed for UWB radio communications. The overall antenna size is $17.3 \times 12 \times 1 \mathrm{~mm}^{3}$. The proposed antenna is simulated with High Frequency Simulation Software (HFSS) and it operation frequency range is $4.1-10 \mathrm{GHz}$ (over $10 \mathrm{~dB}$ ). The antenna radiation characteristics of both E-plane and H-plane are analyzed and studied. Results from the simulation suggest that the proposed antenna is suitable for UWB radio communication applications with good radiation performance and high gain.

\section{REFERENCES}

[1] G. Brzezina, L. Roy, and L. MacEchern, Planar antennas in LTCC technology with transceiver integration capability for ultrawideband applications, IEEE Trans. Microw. Theory Tech., vol. 54, no. 6, 2006, pp. 2830-2839.

[2] C. Ying and Y. P. Zhang, A planar antenna in LTCC for single-package ultrawideband radio, IEEE Trans. Antennas Propag., vol. 53, no. 9, 2005, pp. 3089-3093.

[3] Y. Chen and Y. P. Zhang, Integration of ultra-wideband slot antenna on LTCC substrate, Electron. Lett., vol. 40, 2004 pp. 645646.

[4] J. Liang, L. Guo, C. C. Chiau, and X. Chen, CPW-fed circular disc monopole antenna for UWB applications, Presented at the Proc. IEEE Int. Workshop on Antenna Technology: Small Antennas and Novel Metamaterials, Singapore, $2005,7-9$.

[5] Z. N. Chen, T. S. P. See and X. Qing, Small printed ultra wide band antenna with reduced ground plane effect, IEEE Trans. Antennas. Propag,. Vol. 55, no. 2, 2007, pp. 383-388. 
[6] J. R. Verbiest, and G. A. E. Vandenbosch, A novel small-size printed tapered monopole antenna for UWB WBAN, IEEE Antennas Wireless Propag. lett,. Vol. 5, 2006, pp. 377-379.

[7] S. Radiom, H. Aliakbarian, G. A. E. Vandenbosch, and G. G. E. Gielen, An effective technique for symmetric planar monopole antenna miniaturization, IEEE Trans. Antennas. Propag,. Vol. 57, no. 10, 2009, pp. 2989-2996.

[8] D. Valderas, R. Alvarez, J. Melendez, I. Gurutzeaga, J. Legarda, and J. I. Sancho, UWB staircase-profile printed monopole design, IEEE Antennas Wireless Propag. lett,. Vol. 7, 2008, pp. 255-259.

[9] M. Gopikrishna, D. D. Krishna, C. K. Anandan, P. Mohanan, and K. Vasudevan, Design of a compact semi-elliptic monopole slot antenna for UWB systems, IEEE Trans. Antennas. Propag,. Vol. 57, no. 6, 2009, pp. 1834-1837.

[10] A. M. Abbosh, and M. E. Bialkowski, Design of ultrawideband planar monopole antennas of circular and elliptical shape, IEEE Trans. Antennas. Propag. Vol. 56, no. 1, 2008, pp. 17-23.

[11] T. Dissanayake, and K. P. Esselle, UWB performance of compact Lshaped wide slot antennas, IEEE Trans. Antennas. Propag,. Vol. 56, no. 4, 2008, pp. 1183-1187.

[12] K. S. Ryu, and A. A. Kishk, UWB antenna with single or dual bandnotches for lower WLAN band and upper WLAN band, IEEE Trans. Antennas. Propag,. Vol. 57, no. 12, 2009, pp. 3942-3950.

[13] R. Zaker, C. Ghobadi, and J. Nourinia, Bandwidth enhancement of novel compact single and dual band-notched printed monopole antenna with a pair of L-shaped slots, IEEE Trans. Antennas. Propag,. Vol. 57, no. 12, 2009, pp. 3978-3983.

[14] Q.-X. Chu, and L.-H. Ye, Design of Compact Dual-Wideband Antenna with Assembled Monopoles, IEEE Trans. Antennas. Propag., Vol. 58, no. 12, 2010, pp. 4063-4066.

[15] B. S. Yildirim, B. A. Cetiner, G. Roquetra, and L. Jofre, Integrated Bluetooth and UWB antenna, IEEE Antennas Wireless Propag. lett,. Vol. 8, 2009, pp. 149-152.

[16] High Frequency Structure Simulator V12.1.0, Ansoft Corporation, 2009. 